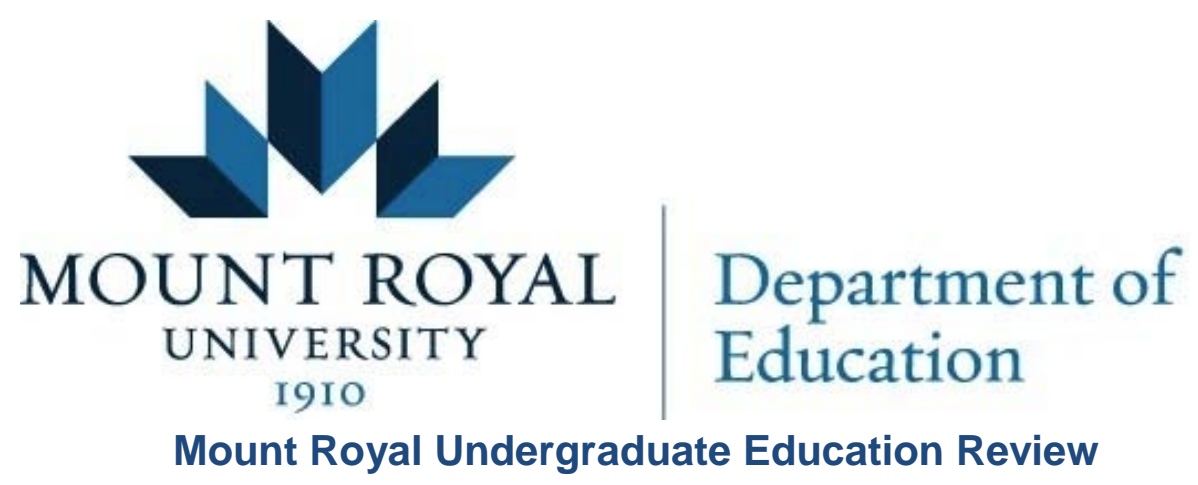

Volume 1(3)

Fall 2015

\title{
Dyslexia and digital technology
}

Taylor Chester, Mount Royal University

\section{Link to Digital Story}

\begin{abstract}
This research manuscript investigates how technology can be used to help students with dyslexia. Using a Google Forms survey and an interview with an expert on the topic, different types of technologies, the pros and cons of using assistive technology, and recommendations for implementing assistive technology in the classroom are listed. It was found that assistive technology is beneficial for students with dyslexia, but each student will benefit from different technologies. The main challenges with assistive technology that this research project uncovered included, glitches, not being user friendly, and the cost of some of these technologies. These problems apply mainly to higher tech assistive technologies, so including low tech assistive technologies in the classroom as well as high tech options could benefit students and avoid some of these challenges. Understanding some of the different assistive technologies that are available and beneficial for students with dyslexia is important for those involved in the education system so that we can give students with dyslexia the tools that they need to succeed. When educators
\end{abstract}


know about, understand how to use, and have the resources to acquire assistive technologies then technology can be used to help students with dyslexia.

\section{Introduction}

As I future teacher there are many areas that I would like to explore in regards to using technology. One area that interests me in particular is the uses of technology in order to create a more inclusive classroom. Over the summer I worked at a camp for children with learning disabilities and I have had friends with learning disabilities. Many of the kids that we had at camp had struggled in school and had low self esteem and self efficacy. If technology can help students in school and help to increase their self-efficacy, then I want to make sure that I am taking full advantage of the technology that is available.

Last year our class visited Dr. Oakley School which is a school specifically for students with learning disabilities. I was able to learn about some of the technologies that Dr. Oakley is using to help students with learning disabilities. I found the technologies that they used really interesting and it got me thinking about what other technologies are available for students with learning disabilities.

As an elementary teacher I know that I will have some students with learning disabilities and I want to make sure that I am creating an inclusive environment for learning. For my inquiry project I would like to examine one learning disability, dyslexia, and find out what types of technology are available to help students with this learning disability. My question is: How can technology be used to help students with dyslexia?

I would like to learn about the technologies available and the pros and cons of some of the assistive technology that students with dyslexia use. Understanding some of the benefits and 
challenges with using some of these technologies will help to inform my future teaching practices when I have students in my class who would benefit from using assistive technology.

\section{Background}

As a part of this research project I have researched technology and its uses in helping students with dyslexia. Exploring and understanding the research that had been done surrounding the topic, provided me with a base of knowledge. Here are some summaries of the materials I have found.

In an article on personal learning materials for students with learning materials Alsobhi, Khan, and Rahanu (2015) examine the assistive technologies and resources for creating learning experiences that meet the needs of students with dyslexia. The material is sorted by the type of dyslexia and the features of the technology .

The book Helping yourself with technology: Making dyslexia work for you covers many topics surrounding Dyslexia. In chapter 11 Goodwin and Thompson (2012) discuss the technology that can be used to help students with dyslexia like audiobooks, text readers, speak to text programs, reading pens, things that can be done with the technology that students are already using to help them, this includes changing the text, font, or colours of text or using a coloured light .

Reid, Strnadová, and Cumming (2013) discuss the use of mobile technology in education for helping students with dyslexia in relation to the principles of UDL. The article provided links to other sites with various applications that can be used to support students with dyslexia. It also identifies the various categories of support such as reading, composing text, and studying and some technologies that are available for each.

Smythe (2010) explores the use of different types of technology in the educational lives 
of dyslexic students in his book: Dyslexia in the digital age making IT work. It examines the types of technology that exist, their usability and benefits. The focus of the book is on the theories and concepts behind the technologies that are discussed as the specific types of technology change rapidly over the years.

Another excellent resource about this topic is a webpage from the international dyslexia association. In the article on the page Winters (2015) examines some types of high and low assistive technology to help students with dyslexia with reading.

I found all of these resources to be very informative. They all listed different types of technologies that will specifically help students with dyslexia. I want to learn more about the benefits and problems with using these technologies. I found all of the information on the technologies interesting, but I also want to learn how they are actually being used in schools.

\section{Research Context}

I collected my data from a few different places. I collected it from Mount Royal University, online, at home and at work. The participants in my study were students and teachers in the education program, people I know with dyslexia, and teachers who I know. These people have experience in the education program and may have come in contact with technologies to aid students with dyslexia. I also know some people who have dyslexia that have used technology that helped them in school. I also interviewed someone with accessibility services at MRU or teachers at Dr. Oakley (a school for students with learning disabilities). In total 13 people participated in my study.

I have completed the research ethics online course and received a certificate. (Here is the link to my certificate) I followed those guidelines when conducting my research in order to ensure that they will not be exposed to risks. I protected their privacy by making the surveys and 
interviews anonymous and participation is optional.

\section{Methods of Investigation}

I used surveys and interviews in order to gather my data. Because I collected data in a number of ways, I analyzed it in multiple ways. I read and categorized the data. For my Google Forms survey I used the Google spreadsheet and graphs of my results in order to compare and contrast the data I collected. I also looked at some of the long answers that I got through my survey and the interview I conducted. As a part of this I have created Wordles with the answers I received and put them into charts. I also interviewed an expert in dyslexia and assistive technology via email and have analyzed my results. The question asked in the Google Forms survey and the interview were about the types of technologies that can be used to support students with dyslexia, their effectiveness, challenges in employing these, and some recommendations for using them.

\section{Findings}

My survey and interview provided me with a plethora of information on how technology can be used to help students with learning disabilities. I was able to learn about how people have used, have hear of or have seen different technologies that can help students with dyslexia. I was interested in seeing what technologies people are using or have heard of instead of just the one I could find online. Below I have unpacked all of my findings from my Google Forms survey and my interview with an expert. 


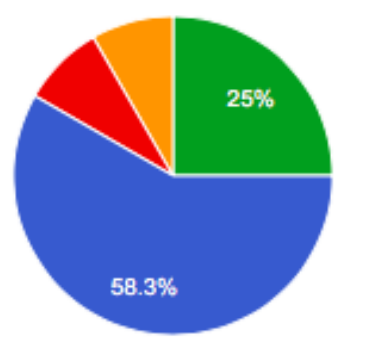

$\begin{array}{rcr}\text { Education Student } & \mathbf{7} & 58.3 \% \\ \text { Elementary Teacher } & \mathbf{1} & 8.3 \% \\ \text { University Teacher } & \mathbf{1} & 8.3 \% \\ \text { Other } & \mathbf{3} & 25 \%\end{array}$

Figure 1. Select the one that best describes you best

For my first few questions I asked the participants some questions in order to get a better understanding of their background knowledge. Most of my participants were education students. As preservice teachers their experience with assistive technology would be from personal experience, observation in field experiences and from readings.

\section{How would you rate your knowledge of assistive technology?}

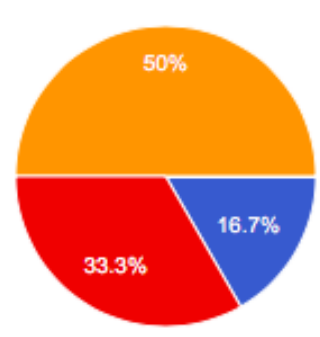

$\begin{array}{rrr}\text { Extremely knowledgeable } & \mathbf{2} & 16.7 \% \\ \text { Fairly knowledgeable } & \mathbf{4} & 33.3 \% \\ \text { Not very knowledgeable } & \mathbf{6} & 50 \% \\ \text { Not knowledgable at all } & \mathbf{0} & 0 \%\end{array}$

Figure 2. Knowledge of assistive technology.

It was interesting to see that although most of my participants are somehow involved in the education system, they don’t feel very knowledgeable about assistive technology. As mentioned before, many of the participants are preservice teachers and would have less classroom experience that may have allowed them to learn more about assistive technology. Even so, I was encouraged by the fact that 6 participants did feel knowledgeable about assistive technology. If you are a part of the educational system it is likely that you will encounter a student with dyslexia and being educated on some of the technologies available to help these 
students, is important. I included a description in here of what assistive technology is: any tool (electronic or not) that can help someone do something that would have been difficult or impossible for the person to do without it. I found that in my conversations with people about this topic many people thought of electronics, computer programs and apps but didn't realize that there are many non-electronic things that are assistive technology.

Which types of assistive technology are you most familiar with (you may select more than one)

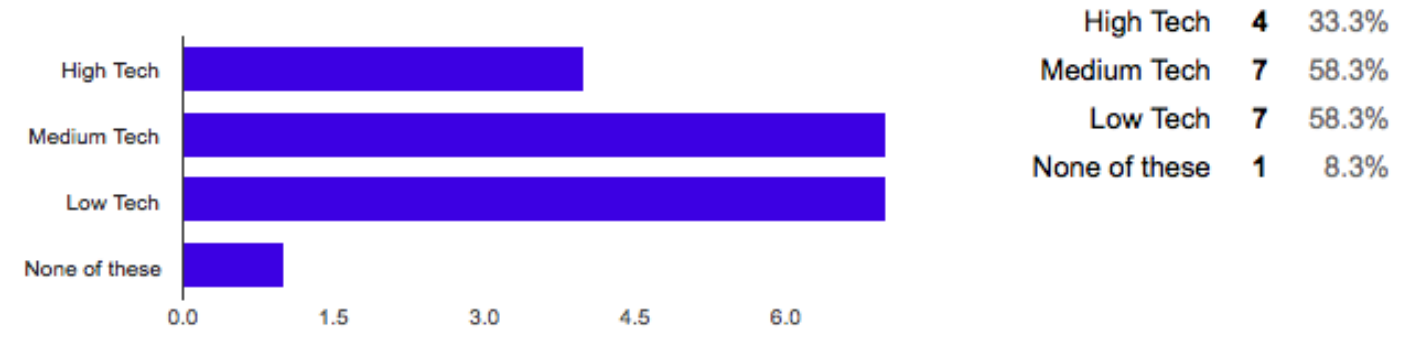

Figure 3. Familiarity with assistive technology

For this question I included a description of the differences between these types of technologies: Low tech: these are simple technologies without electricity, like pencil grips, coloured paper etc. Medium tech could be a calculator and high tech could include computer programs or smart devices. There are many effective low tech assistive technologies but they are not always recognized as being a type of assistive technology. Although many participants indicated that were most familiar with low tech types of technologies, I noticed that later in my survey (see table 1) the technologies described were mostly high tech.

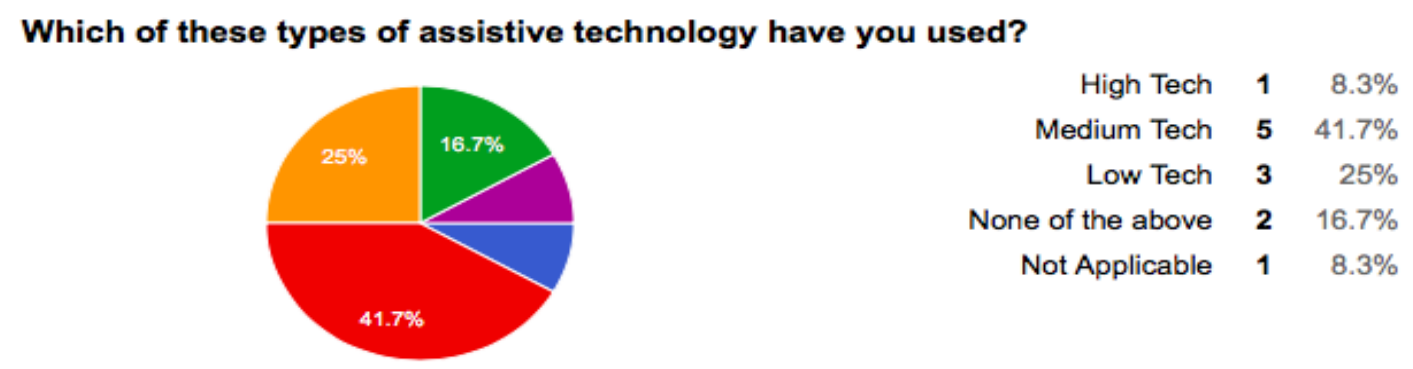

Figure 4. Types of assistive technology they have used 
This question is similar to the previous one. In this question I wanted to find out how many of my participants had actually used assistive technologies. Mainly medium and low tech were used by the participants and it was helpful to see what types of technologies people are actually using. There are many high tech options but in my survey only 1 person had used a high tech technology. The reasons behind this are something I would like to examine and some explanations are listed in later questions.

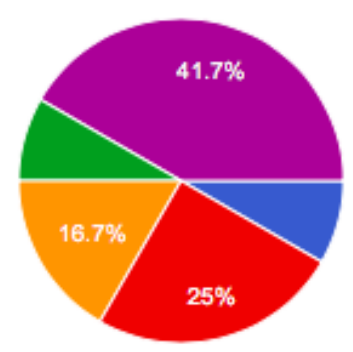

$\begin{array}{rcr}\text { High Tech } & \mathbf{1} & 8.3 \% \\ \text { Medium Tech } & \mathbf{3} & 25 \% \\ \text { Low Tech } & \mathbf{2} & 16.7 \% \\ \text { None of the above } & \mathbf{1} & 8.3 \% \\ \text { Not Applicable } & \mathbf{5} & 41.7 \%\end{array}$

Figure 5. Types of assistive technology that teachers have employed

Of the teachers that answered this questions, a variety of types of assistive technology were used. This is encouraging. As teachers it is important to understand and use a variety of technologies in order to help your students because not one student is the same. Students also may require multiple types of technology in their learning. Having these options available to students is important. Some of the reasons why teachers may not employ all of these types of technologies could be lack of knowledge about the types, the availability and the cost of some technologies. 


\title{
Have you experienced any challenges in employing or using assistive technology?
}

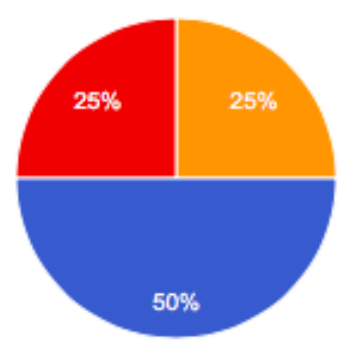

\author{
Yes $650 \%$ \\ No $325 \%$ \\ Not Applicable $3 \quad 25 \%$
}

Figure 6. Challenges with assistive technology

Of the participants who had experience with assistive technology, 6/9 of them have experienced challenges. These challenges could be some of the reasons why teachers struggle to implement these types of technologies. Understanding these challenges is important in understanding what types of technologies are effective and finding ways to overcome some of these technologies so that they can be used more in the classroom and be more beneficial to students. Some of these challenges will be examined belo

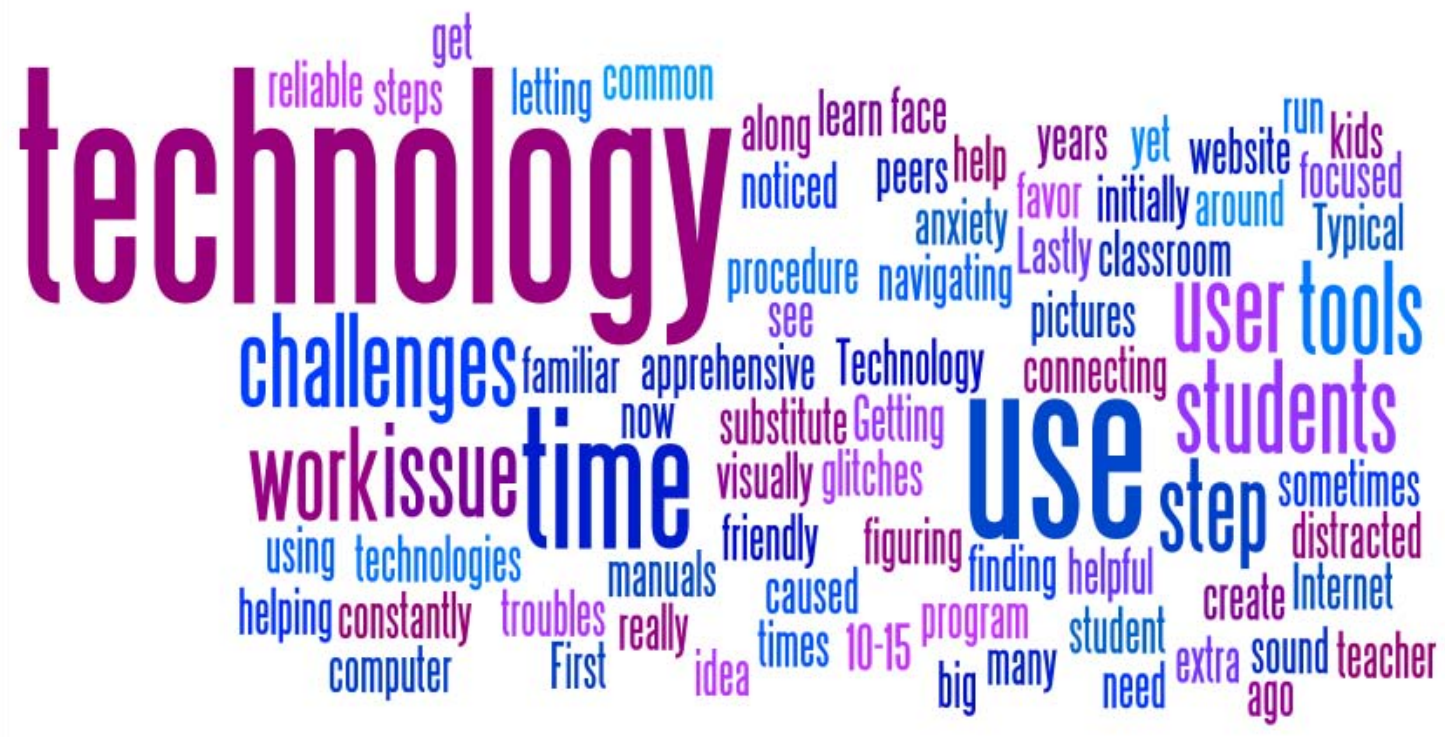

Figure 7. A wordle about the challenges in using assistive technology 
Some of the challenges that stood out in this wordle were reliable, students, navigating, finding, and time. Some of these challenges would vary based on the technology being used. Navigating and reliability challenges would apply more to high tech types. By educating teachers on how to use them and finding ways to make them more reliable would help to overcome these struggles. Finding them and having the time to learn, teach, and use these in the classroom are problems that might occur when using any type. In terms of finding these effective technologies, teachers should do research into technologies and work with other teachers to discuss different types, how to implement them and their effectiveness. Assistive technology is something that schools should also look at in order to have some technologies that all teachers in the school understand and can use.

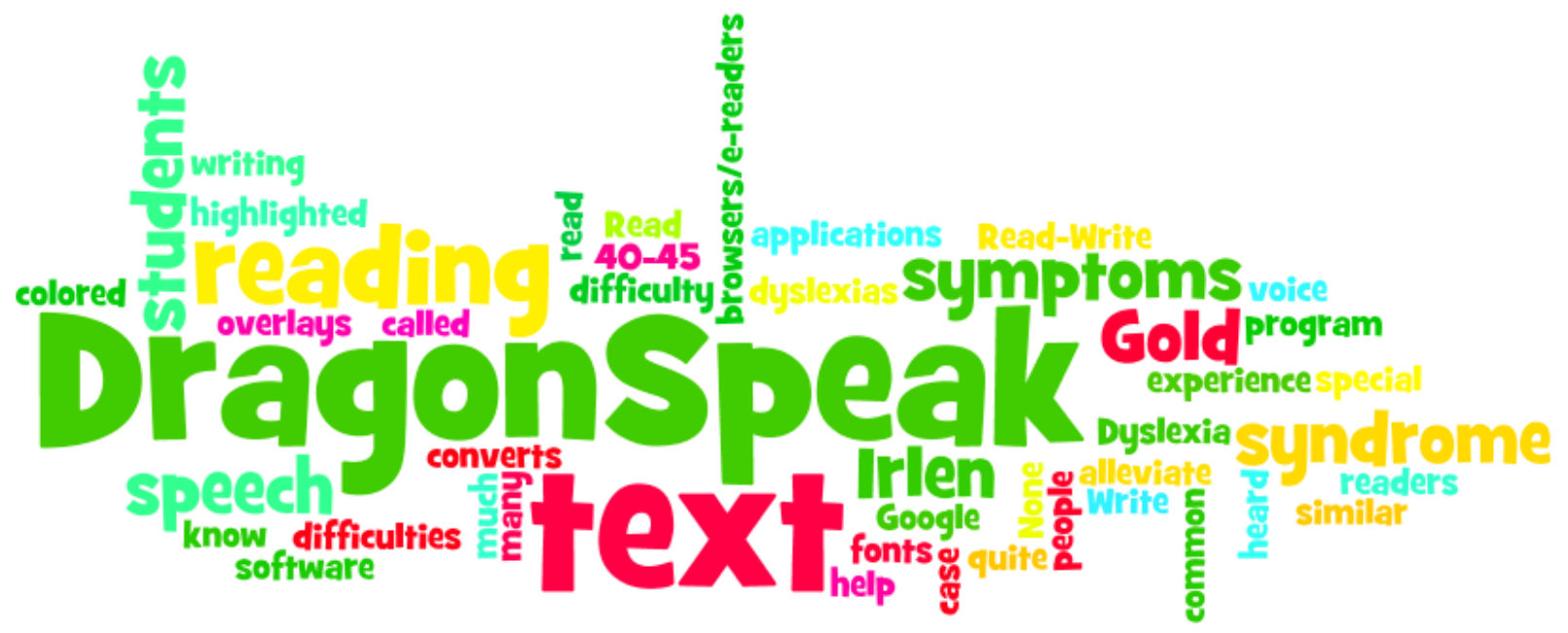

Figure 8. A wordle on different types of assistive technology

The most commonly listed technology was DragonSpeak, this is a text to speak, and speech to text program that can be used on computers, Read-Write Gold, software, browsers and e-readers were some of the higher and medium techs listed. Some lower techs listed were fonts, 
coloured and overlays. This can mean printing out things in different fonts, on coloured paper or getting students to use coloured paper for their work.

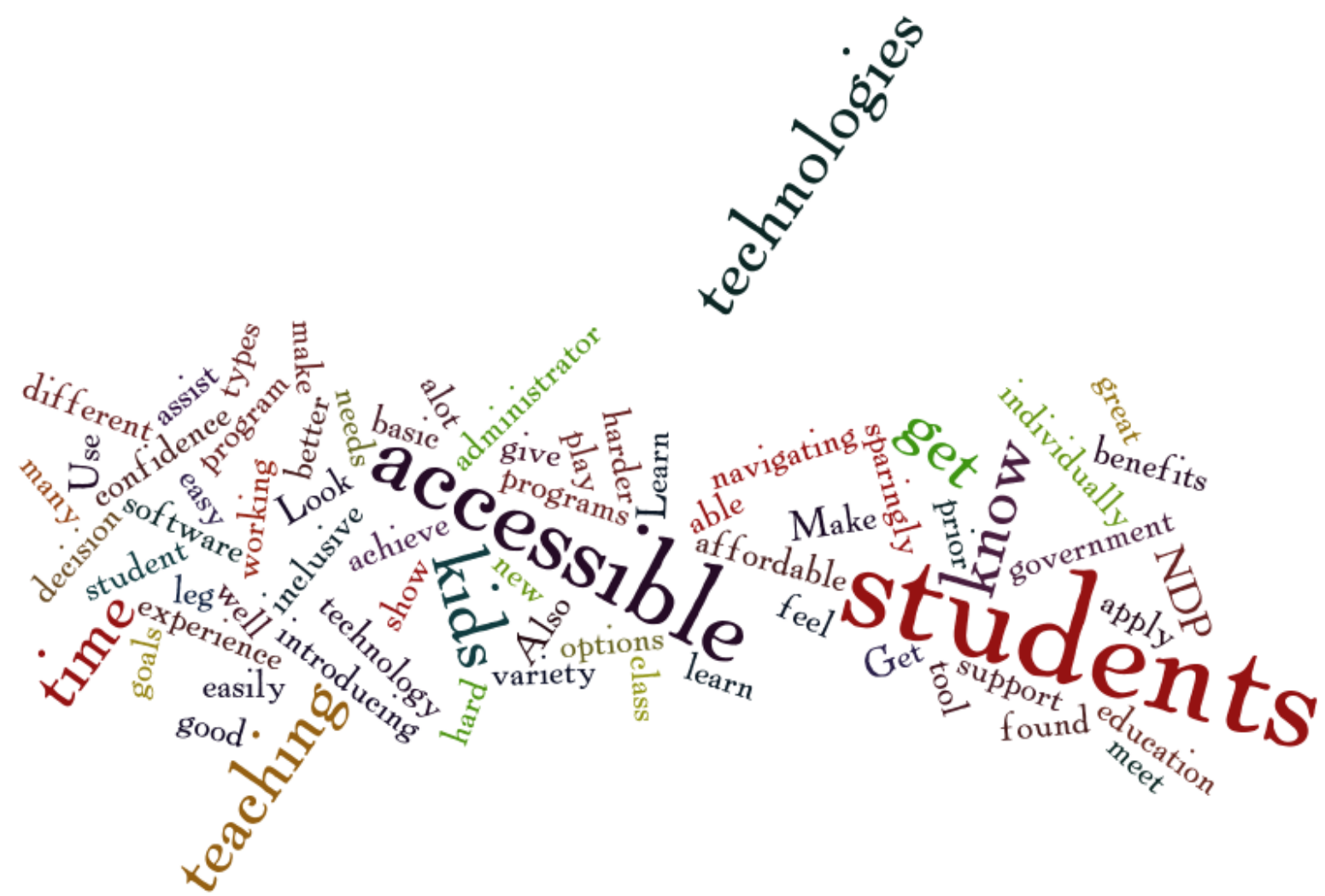

Figure 9. Wordle themes on the effectiveness of different technologies

The most common word listed in this question was students. This is what it is all about. If assistive technology is helping the student to learn and supporting them then it is effective. Some other themes were support, meet needs, teaching, and confidence, these are all reasons why assistive technology is effective. It supports students, meets their needs, helps us to teach our students better, and can build their confidence because they are getting the support they need to be successful. 


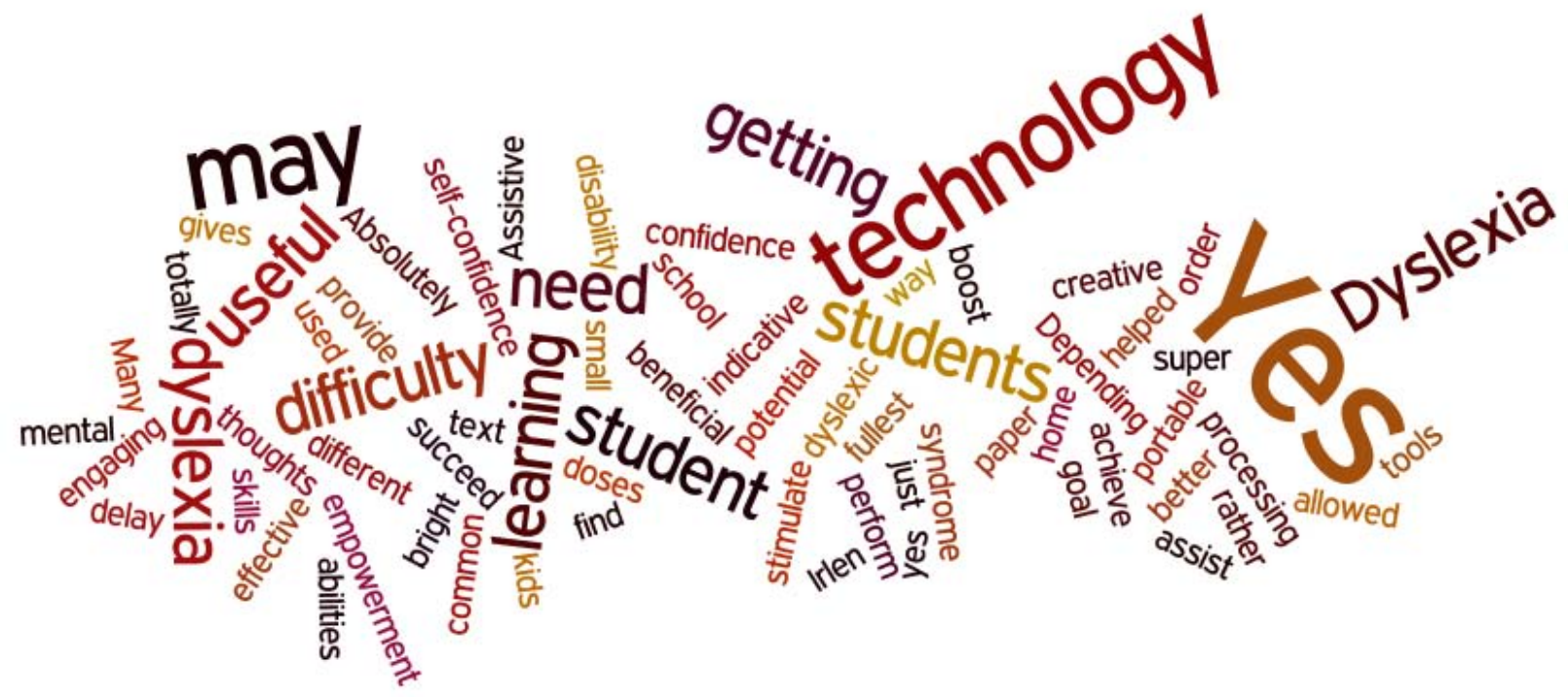

Figure 10. Wordle themes on whether using assistive technology is beneficial for students with dyslexia

The most common word was yes. The participants in the survey believe, have seen, or have experienced the benefits of using assistive technology. As it is beneficial to students, bringing these technologies into the classroom is important for student learning. Confidence and self-confidence were both indicated in this question. Many students with learning disabilities have a low self-efficacy and confidence because they struggle to express what they know or read information. When technology is able to help them to read and express their learning then students can be successful and this will increase their self-efficacy which is so important. 


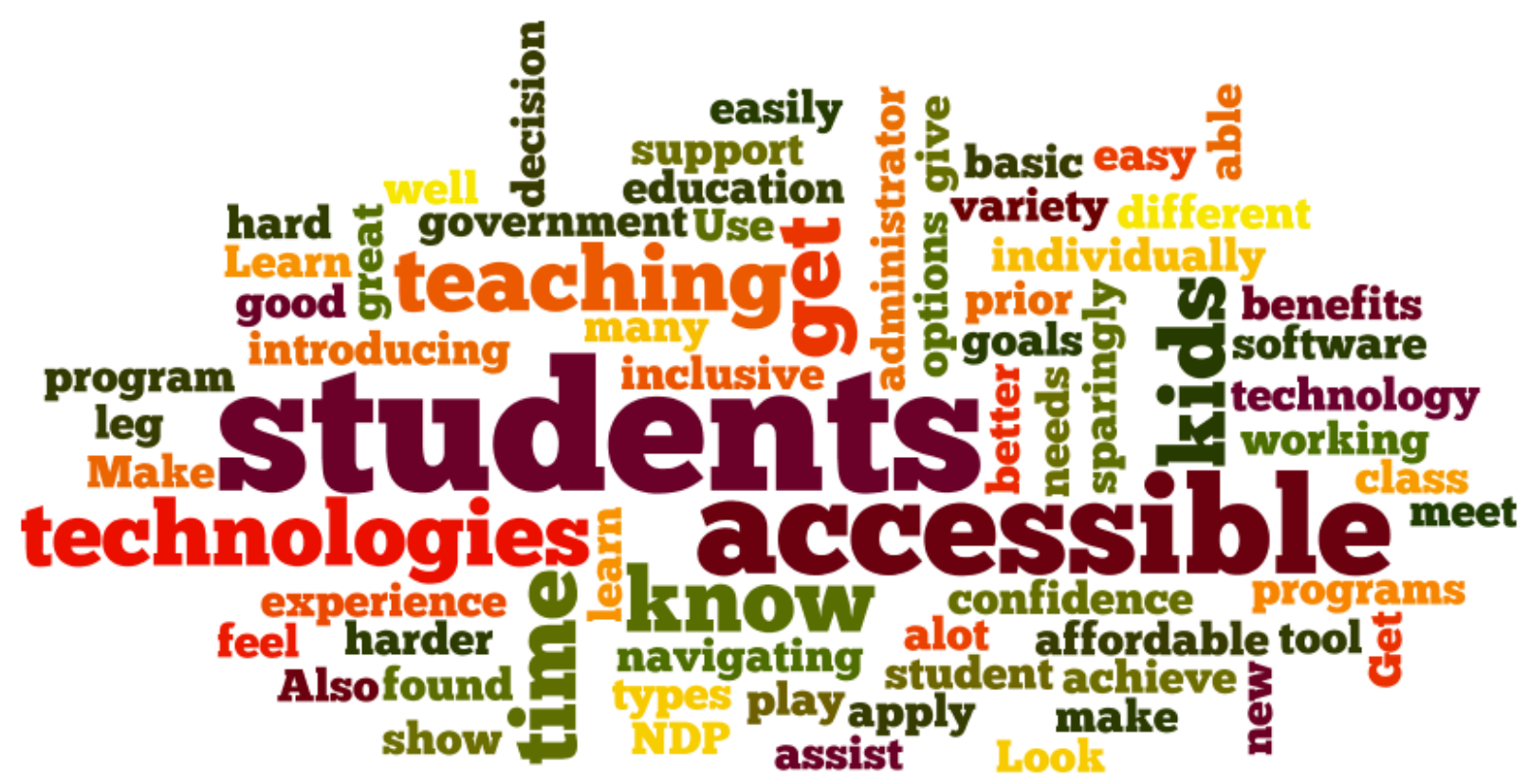

Figure 11. Wordle themes about recommendations and strategies for incorporating assistive technology in the classroom

Students is one of the most common words. As a teacher I want this to be my focus when integrating assistive technology into the classroom. Every student is different. This is the same for students with dyslexia getting to know the needs of individual students is important. One technology will not necessarily help every student with dyslexia. Students also need to be able to use and access the technology easily. If they struggle using it then it won't be beneficial to their learning.

Table 1

Key themes about using technology to help students with dyslexia in the classroom.

\begin{tabular}{|l|l|}
\hline Key Themes & Corresponding Participant Comment \\
\hline $\begin{array}{l}\text { Challenges in } \\
\text { using assistive } \\
\text { technology }\end{array}$ & $\begin{array}{l}\text { As a student using these technologies, I did face some challenges. First } \\
\text { was if the technology did not work or there was an issue, it caused me } \\
\text { extra anxiety. At the time, technology wasn't as common in the classroom }\end{array}$ \\
\hline
\end{tabular}




\begin{tabular}{|c|c|}
\hline (7 comments) & $\begin{array}{l}\text { so from time to time I would run into a substitute teacher who was } \\
\text { apprehensive to letting me use the technology. Lastly, there was some } \\
\text { times where my use of technology was noticed by my peers. I don't see } \\
\text { this as being as big of an issue now, as students are more familiar with } \\
\text { having technology all around them than they were 10-15 years ago. } \\
\text { Getting kids to be focused or constantly helping students that had no idea } \\
\text { what they were doing. } \\
\text { Typical computer glitches, figuring out how to use the tools, finding that } \\
\text { some tools are not as helpful as they initially sound... } \\
\text { Not being user friendly to the user because there are too many steps. We } \\
\text { would have to create procedure manuals with step by step to help along } \\
\text { with pictures for those who need to learn visually. }\end{array}$ \\
\hline $\begin{array}{l}\text { Types of } \\
\text { technologies } \\
\text { (10 comments) }\end{array}$ & $\begin{array}{l}\text {...Colored overlays can help alleviate symptoms } \\
\text {...special fonts for browsers/e-readers } \\
\text { Dragon-speak, Google Read-Write, voice to text applications, text } \\
\text { readers, highlighted and read text }\end{array}$ \\
\hline $\begin{array}{l}\text { Effectiveness } \\
\text { of the } \\
\text { technology } \\
\text { ( } 7 \text { comments) }\end{array}$ & $\begin{array}{l}\text { Google Read-Write } 8 \text { Voice to text application } 8 \\
\text { Overlays are very effective for those less severe, tinted glasses/contacts } \\
\text { are very effective for those very to extremely severe } \\
\text { Fonts - } 10 \\
\text { Tumble Books - } 9 \text {.. students can follow along and read and the books } \\
\text { highlight every word that is being said. it's a great way for students to } \\
\text { learn how to read. } \\
\text { 8-Computer with text to speech software or word processor }\end{array}$ \\
\hline $\begin{array}{l}\text { The benefits of } \\
\text { using assistive } \\
\text { technology } \\
\text { (10 comments) }\end{array}$ & $\begin{array}{l}\text { Assistive technology is super beneficial for students of all abilities. It } \\
\text { gives students with Dyslexia the tools that they need to perform at their } \\
\text { fullest potential. }\end{array}$ \\
\hline
\end{tabular}




\begin{tabular}{|l|l|}
\hline Recommendat & $\begin{array}{l}\text { It helped boost confidence and allowed for the student to succeed without the } \\
\text { learning disability getting in the way. } \\
\text { (7 comments) }\end{array}$ \\
$\begin{array}{l}\text { Provide self-confidence and empowerment !! } \\
\text { introducing it to your students because if you have a hard time navigating } \\
\text { through the program, they will have a harder time. If you can show your } \\
\text { students all the great benefits and apply it to their teaching it will give } \\
\text { your students confidence. And a leg up to achieve their goals. } \\
\text { Look for technologies that can be easily accessible and easy to learn by } \\
\text { both the student and the administrator. } \\
\text { Get all of the experience you can with different types of technologies. } \\
\text { Also get to know the kids you are working with. I feel that once you know } \\
\text { the kids individually, you will be able to make a better decision on how to } \\
\text { assist the students in your class. } \\
\text { A good tool will meet a variety of needs. And many can be found in basic } \\
\text { software programs. }\end{array}$ \\
\hline
\end{tabular}

These answers were all collected from my survey. I was able to see some types of technology that my participants have used or heard of. The challenges addressed were mainly about the cost and accessibility of the more high tech technologies. I found that many participants found the technology effective for helping students with technologies. Getting to know the student and what works for them, learning the technology yourself, and finding tools that can meet a variety of need were some of the recommendations from my participants. I asked additional questions to an expert in the field in order to get more information on these topics. She listed, TextHelp, Read and Write Gold, Kurzweil, and screen readers like Read Please, Read Outloud, MS word, and Adobe as some high tech softwares. One challenge she identified was 
how students can become overwhelmed with the addition of new technology. Some students may not want to try something new and introducing a new type of technology might be overwhelming for some students. By slowing introducing these technologies and helping them with the technologies, this can be a much better experience for students. Her recommendation for me when I am using assistive technologies in the class was to talk to my students. This is very similar to the suggestions made by some of the survey participants. She suggested I "Ease them into learning about the technology, make it fun and less of a chore (Unknown, personal communication, 2015)" She also recommended I make that my students know that the technology can help them when used correctly. But she also pointed out that every student is different and will benefit from different technologies.

\section{Conclusions and Recommendations}

Through this study I was able to see that technology can be used to help students with dyslexia and increase their self-confidence. The participants in my survey identified how giving technological tools (through technology) to help them reach their full potential is able to boost their self-confidence. Giving students this is so important, therefore teachers need to be educated on the types of technologies that are available to help students- low medium and high tech options. I found that although most of my participants were involved in the educational system, they didn't know very much about assistive technology. This gap between their belief about the importance of using technology and knowledge about technologies, raises some further questions; why does this gap exist and how can it be bridged? These questions need to be explored in order to make sure that teachers know about and are able to use assistive technologies in their classrooms.

There are many ways that technology can be used in order to help students with dyslexia 
and this study has identified some of these tools that I could implement in my classroom as a teacher in order to help my students. Learning about these technologies while also being informed of some of the challenges that could occur has prepared me to be able to use some of these technologies.

There are many different technologies available but they are not a 'one-size-fits-all'. As educators, it is important to figure out what technologies would be most beneficial to the student. This student centered approach is so important and must not be overlooked. Buying an expensive, high tech, software for a student isn't helpful if it isn't user-friendly and the student struggles to use it. This will create more stress for the student and won’t be beneficial. By working with the student to find out what they need and what will help them, will allow us to use assistive technology in a more beneficial way.

Some other questions that this study raised were: How can these technologies be made more accessible? and how can some of the challenges- glitches in the technology or not being user friendliness- be overcome? As these questions are answered and solutions are found, technology will be able to be used more effectively to help students with dyslexia.

\section{References}

Alsobhi, A., Khan, N., \& Rahanu, H. (2015). Personalised learning materials based on dyslexia types: Ontological approach. Procedia Computer Science, 60, 113-121. http://dx.doi.org/doi:10.1016/j.procs.2015.08.110

Goodwin, V., \& Thomson, B. (2012). Helping yourself with technology. In making dyslexia work for you (2nd ed.). London: Routledge.

Reid, G., Strnadová, I., \& Cumming, T. (2013). Expanding horizons for students with dyslexia in the 21st century: Universal design and mobile technology. Journal of Research in 
Special Educational Needs, 13(3), 175-181. doi:10.1111/1471-3802.12013

Smythe, I. (2010). Dyslexia in the digital age making IT work. London: Continuum International Pub. Group.

Winters, D. (2015, February). Dr. Dave’s AT Lab. Retrieved October 2, 2015, from http:/ /eida.org/dr-daves-at-lab/ 